\title{
RELEVANSI PENGGEMBALAAN PAULUS DALAM I KORINTUS 3:1-9 TERHADAP PENJANGKAUAN ANAK MUDA DI GBI PASKO BANDUNG
}

\author{
Victoria Eva Aryanti, Jessica E. Abraham, Christopher Santoso, Victor Deak \\ Sekolah Tinggi Teologi Kharisma Bandung \\ Evavictoria624@gmail.com
}

\begin{abstract}
Conflict is one of the church's problems, which often results in division and decreased participation of the congregation in fellowship. This paper aims to describe the Apostle Paul's pastoral strategy, as stated in 1 Corinthians 3: 1-9, and its relevance to youth outreach at GBI Pasko Bandung using qualitative methods and literature study. From this research, it was found that the Apostle Paul's pastoral strategy was: (1) Paul tried to create positive communication, (2) Paul tried to connect his ministry practice with Christian teachings, (3) used letter media to overcome communication difficulties at that time. The relevance of shepherding youth at GBI Pasko Bandung is: (1) shepherding youth with positive communication, (2) inviting young people to face differences in an adult manner, (3) strengthening the faith of young people by teaching, Also, to overcome the limitations of reaching young people, various communication media nowadays such as gadgets can be used so that they can be touched personally.
\end{abstract}

Keywords: pastoral strategy, apostle Paul, adult, young people, conflict

Abstrak. Konflik merupakan salah satu persoalan yang dihadapi gereja yang seringkali mengakibatkan perpecahan dan penurunan partisipasi jemaat dalam persekutuan. Tulisan ini bertujuan untuk mendeskripsikan strategi penggembalaan Rasul Paulus sebagaimana tertuang dalam 1 Korintus 3:1-9 dan relevansinya terhadap penjangkauan anak muda di GBI Pasko Bandung dengan menggunakan metode kualitatif dan studi pustaka. Dari penelitian ini ditemukan bahwa strategi penggembalaan Rasul Paulus adalah: (1) Paulus berusaha menciptakan komunikasi yang positif, (2) Paulus berusaha menghubungkan praktek pelayanan dengan ajaran Kristen, (3) menggunakan media surat untuk mengatasi kesulitan berkomunikasi pada waktu itu. Relevansinya dalam penggembalaan anak muda di GBI Pasko Bandung adalah: (1) menggembalakan anak muda dengan komunikasi yang positif, (2) mengajak anak muda menghadapi perbedaan secara dewasa, (3) menguatkan iman anak muda dengan pengajaran. Selain itu untuk mengatasi keterbatasan menjangkau anak-anak muda bisa menggunakan berbagai media komunikasi dewasa ini seperti gagdet agar mereka bisa disentuh secara personal.

Kata Kunci: strategi penggembalaan, Rasul Paulus, dewasa, anak muda, konflik

\section{PENDAHULUAN}

Penggembalaan sangat penting di gereja terkhusus untuk jemaat karena gembala merupakan pembimbing rohani, bukan saja dalam memberikan arahan 
BONAFIDE: Jurnal Teologi dan Pendidikan Kristen

www.jurnal.sttissiau.ac.id/Volume 1/Nomor 2/Desember 2020/hal.279-292

moral tetapi mempunyai semangat dalam pemberitaan Firman Tuhan. Seorang gembala adalah orang yang Tuhan panggil untuk memperhatikan domba. "Gembala adalah pemimpin yang memberi pertumbuhan rohani kepada Sang Pemilik domba yaitu Kepala Gembala.”(Rupa, 2016, hal. 170)

Di dalam Alkitab, umat Tuhan disebut domba dan Tuhan mengangkat orang-orang yang disebut gembala untuk memperhatikan kawanan domba. Jadi, penggembalaan dilakukan untuk melaksanakan tugas dan tanggung jawab untuk pertumbuhan gereja. Penggembalaan yang baik bertujuan supaya jemaat Yesus Kristus dapat dibangun dan hidup serta turut bertanggung jawab dalam pelayanan. Kalau dalam jemaat tiap-tiap anggota menjadi anggota yang hidup, yang tahu akan panggilannya, maka jemaat itu akan menjadi suatu jemaat yang hidup. Anggota jemaat memerlukan bimbingan dan penggembalaan untuk mengetahui bagaimana anggota jemaat bisa hidup sebagai pengikut Kristus. Telaumbanua mengatakan, "gembala sidang tidak hanya menggembalakan dan memberitakan Injil saja, tetapi juga mendidik, mengajar jemaat secara efektif, kreatif, inovatif dan dinamis serta melaksanakan pembelajaran secara aktif, kreatif, efektif dan menyenangkan. Dengan pendidikan seperti ini, pertumbuhan rohani jemaat dapat terjadi.”(Telaumbanua, 2019, hal. 365)

Di dalam Alkitab ada seorang yang melakukan tugas penggembalaan kepada jemaat yaitu Rasul Paulus. Rasul Paulus sebelumnya memiliki nama Saulus yang diambil dari bahasa Ibrani, tetapi sesudah bertobat mengambil nama dalam bahasa Yunani, yaitu Paulus. Rasul Paulus muncul dalam Alkitab sebagai orang Yahudi fanatik yang menentang jemaat Kristen, melakukan penganiayaan 
BONAFIDE: Jurnal Teologi dan Pendidikan Kristen

www.jurnal.sttissiau.ac.id/Volume 1/Nomor 2/Desember 2020/hal.279-292

dan menganiaya jemaat untuk diserahkan kepada pengadilan Mahkamah Agama Yahudi (Kis. 8:3). (Yusmasari, 2018).

Rasul Paulus adalah seorang bangsa Yahudi termasuk golongan farisi, murid dari rabi Gamaliel di Yerusalem. Paulus dilahirkan di Tarsus, provinsi Kilikia. Dalam perjumpaannya dengan Tuhan menuju Damsyik, Saulus berubah menjadi seorang pengikut Yesus dan masuk dalam persekutuan bersama orangorang Kristen. Dari hal ini, Rasul Paulus memulai perjalanannya dalam pemberitaan Injil. (Yusmasari, 2018).

Dalam penggembalaannya Rasul Paulus sangat memperhatikan jemaat. Kalau ia tidak berkesempatan untuk mengunjungi jemaat-jemaat itu, ia menulis surat.(Gereja Yesus Kristus, n.d.) Bahkan tiga di antaranya, yaitu Surat Titus, Filemon, dan Timotius disebut sebagai surat-surat penggembalaan.(Sudjarwo, 2019) Dalam surat-surat itu diungkapkan tentang kasih kepada saudarasaudaranya dalam jemaat, keinginan untuk bergaul dan bertukar pikiran dengan mereka dan juga keinsyafan, bahwa Tuhanlah yang menyuruh manusia untuk saling menolong dan saling dibimbing. Tujuan surat-surat itu adalah untuk membangun jemaat.

Dengan demikian, dalam penggembalaan bahwa yang dituntut adalah membangun relasi yang baik kepada jemaat supaya membawa jemaat mengalami suatu pengenalan akan Allah. J.W Herfst mengatakan penggembalaan itu ialah menolong orang lain untuk menyadari hubungannya dengan Allah dan mengajarnya untuk taat kepada Allah dan sesamanya berdasarkan situasinya sendiri.(dalam Bons-Storm, 1967) 
BONAFIDE: Jurnal Teologi dan Pendidikan Kristen

www.jurnal.sttissiau.ac.id/Volume 1/Nomor 2/Desember 2020/hal.279-292

Dalam penggembalaan komunikasi sangatlah penting. Franz-Josef Eilers mengemukakan bahwa komunikasi penggembalaan atau pastoral "dikaitkan dengan berbagai sarana, metode serta kandungan komunikasi yang dibutuhkan seorang gembala agar dapat berkomunikasi dengan dan memelihara kawanannya.”(dalam Wijaya, 2012)

Dalam penelitiannya terhadap pengaruh komunikasi gembala sidang terhadap keaktifan pengerja gereja, Hura menemukan beberapa indikator penting dalam komunikasi gembala: (1) untuk membangun persekutuan, (2) untuk menciptakan ruang diskusi agar bisa berbagi informasi dan pengalaman, (3) menjalankan peran sebagai motivator, (4) menjadi teladan, (5) penggunaan media elektronik.(Hura, 2020)

Dapat disimpulkan bahwa dalam penggembalaan dibutuhkan seorang yang cakap berkomunikasi dalam pengajaran sehingga pelayanannya mengalami pertumbuhan rohani, khususnya terhadap iman jemaat. Penggembalaan tanpa kemampuan berkomunikasi akan sulit membawa pertumbuhan rohani karena Allah menggunakan berbagai sarana untuk mengkomunikasikan Injil kepada banyak orang lewat khotbah, perumpamaan, ilustrasi, maupun pernyataan-Nya sendiri.

Penulis mengamati ada masalah dalam penggembalaan komunitas anak muda di GBI Pasko Bandung. Jumlah anggota komunitas yang aktif dalam ibadah semakin menurun dari waktu ke waktu sebagaimana tergambar pada tabel berkut.

Tabel 1. Jumlah kehadiran komunitas Link Youth GBI Pasko Bandung tahun 2013-2019 


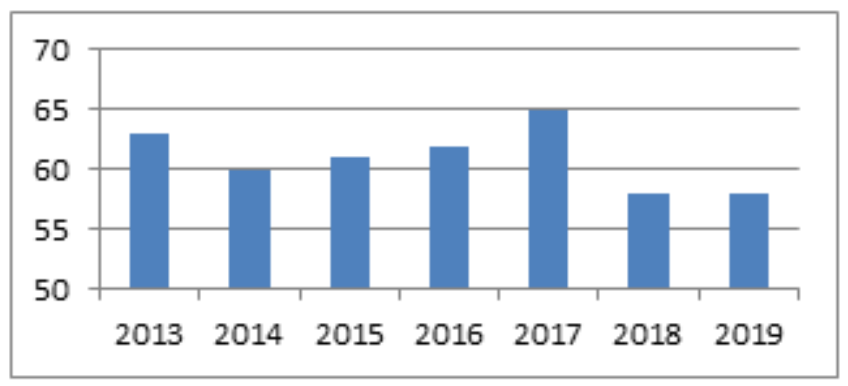

Dari tabel di atas nampak bahwa ada penurunan jumlah komunitas anak muda GBI Pasko Bandung berdasarkan data tujuh tahun terakhir ini. Tahun 2013 dengan jumlah keseluruhan 63 orang yang hadir. Tahun 2014 dengan jumlah keseluruhan 62 orang yang hadir. Tahun 2015 dengan jumlah keseluruhan 61 orang orang yang hadir. Tahun 2016 dengan jumlah keseluruhan 62 orang yang hadir. sementara, pada tahun 2017 dengan jumlah keseluruhan 65 orang yang hadir. Sedangkan tahun 2018-2019 mengalami penurunan dengan jumlah keseluruhan 58 orang yang hadir.

Berdasarkan hasil wawancara dengan ketua komunitas anak muda GBI Pasko yang disebut Link Youth tampaknya masalah yang dominan adalah adanya perbedaan budaya yang membuat terbentuknya kelompok-kelompok di kalangan anak-anak muda ini dan berdampak pada penurunan keterlibatan mereka dalam ibadah. Selain adanya perbedaan budaya, masalah lain adalah penerapan kebijakan pelayanan yang bertujuan mendisiplinkan anak-anak muda. Tampaknya kebijakan ini membawa dampak ketidakpuasan yang mengakibatkan memudarnya ikatan persekutuan. Padahal ikatan persekutuan merupakan penggerak dalam kehadiran dan keaktifan kaum muda dalam persekutuan. 
BONAFIDE: Jurnal Teologi dan Pendidikan Kristen

www.jurnal.sttissiau.ac.id/Volume 1/Nomor 2/Desember 2020/hal.279-292

Masalah ini tampak serupa dengan masalah yang dihadapi oleh jemaat Korintus di bawah penggembalaan Rasul Paulus sebagaimana digambarkan dalam 1 Korintus 3:1-9. Pada waktu itu terjadi konflik di jemaat Korintus. Ada empat kelompok yang muncul dan berkonflik dalam pelayanan di jemaat, yaitu kelompok Paulus, kelompok Apolos, kelompok Kefas, dan kelompok yang menamakan diri kelompok Kristus (1 Kor 1:12). Konflik ini membawa dampak negatif kepada jemaat, yaitu jemaat tidak berkembang atau bertumbuh. Dalam ayat 2 Paulus mengatakan "Susulah yang kuberikan kepadamu, bukanlah makanan keras, sebab kamu belum dapat menerimanya. Dan sekarang pun kamu belum dapat menerimanya.”(Filadelfia, 2015)

Perikop ini, 1 Kor 3:1-9 berisi, penggembalaan Paulus kepada para anggota jemaat yang berkonflik tersebut. Artikel pada blog www.filadelfiadumai.blogspot.com menyebutkan bahwa ada empat hal penting dalam perikop yang merupakan solusi Paulus atas konflik tersebut: (1) memberi nasehat; (2) menjelaskan bahwa semua pemberita Injil sama saja; (3) merendahkan diri; (4) menyadarkan bahwa gereja adalah milik Allah. (Filadelfia, 2015)

Penggembalaan Paulus untuk mengatasi konflik di jemaat ini menarik untuk dikaji dalam rangka menemukan relevansinya untuk menjawab permasalahan kurang aktifnya kaum muda GBI Pasko Bandung. Oleh karena itu, penulis bertujuan mendeskripsikan relevansi strategi penggembalaan Rasul Paulus dalam 1 Korintus 3:1-9 terhadap permasalahan komunitas anak muda di GBI Pasko Bandung. Penelitian ini menjadi unik karena memberikan penekanan 
BONAFIDE: Jurnal Teologi dan Pendidikan Kristen

www.jurnal.sttissiau.ac.id/Volume 1/Nomor 2/Desember 2020/hal.279-292

kepada aplikasinya bagi kaum muda, bagaimana anak muda diajarkan cara menghadapi konflik dalam pelayanan agar tidak berdampak negatif bagi kaum muda itu sendiri maupun pelayanan dalam gereja.

\section{METODE PENELITIAN}

Metode yang penulis gunakan untuk melaksanakan penelitian adalah metode kualitatif dan studi pustaka. Untuk studi lapangan, subyek penelitiannya adalah GBI Pasko No 39 di jalan Pasir Koja No. 39 Bandung, dan segi kajian biblika obyek kajiannya adalah 1 Korintus 3:1-9 mengenai perpecahan jemaat. Strategi penggembalaan Rasul Paulus dan aplikasinya terhadap penjangkauan anak muda di GBI Pasko Bandung menjadi objek dari penelitian ini.

Teknik pengumpulan data yang digunakan untuk mengetahui permasalahn pelayanan pada komunitas anak muda (Link Youth) GBI Pasko Bandung adalah wawancara dengan melibatkan lima orang informan, yaitu ketua komunitas anak muda (Link Youth) GBI Pasko Bandung dan empat orang jemaat anak muda. Untuk mendapatkan pemahaman mengenai strategi pengembalaan Paulus, penulis mengumpulkan data dengan studi kepustakaan dengan fokus pada pendapat para ahli biblika mengenai strategi Paulus tersebut.

\section{HASIL PENELITIAN}

\section{Strategi Penggembalaan Rasul Paulus}

Dalam menghadapi permasalahan di Jemaat Korintus Paulus menjalankan strategi penggembalaan berikut ini. 
BONAFIDE: Jurnal Teologi dan Pendidikan Kristen

www.jurnal.sttissiau.ac.id/Volume 1/Nomor 2/Desember 2020/hal.279-292

Pertama, pendekatan dasar Rasul Paulus ialah menciptakan iklim yang positif melalui komunikasi untuk menyelesaikan masalah jemaat di Korintus dengan memberikan suatu ajaran. 2 Korintus 13:11 merupakan dasar komunikasi. Rasul Paulus memberikan nasehat untuk "Sehati sepikirlah kamu, dan hiduplah dalam damai sejahtera". Dengan berkomunikasi akan membangun hubungan yang baik dengan sesama.

Kedua, Rasul Paulus selalu teliti dalam mengaitkan praktik dengan ajaran. Hal ini bertujuan supaya jemaat di Korintus dapat memahami dan bersandar pada ajaran dalam kehidupan sehari-hari. Di dalam ajaran tersebut Rasul Paulus mengingatkan jemaat bahwa mereka adalah kawan sekerja Allah, ladang Allah dan bangunan Allah yang berada dalam minister Allah (1 Kor.3:9).

Ketiga, strategi Rasul Paulus yaitu mengajarkan pokok iman melalui surat yang dikirimkan dengan maksudnya untuk menghasilkan kedewasaan ialah perhatiannya untuk memungkinkan orang percaya agar menyelesaikan masalahmasalah bagi diri mereka sendiri.

Strategi penggembalaan Rasul Paulus dapat diringkaskan oleh kata-kata seperti memberi dorongan, memberi kemampuan, uraian, teladan, dan nasihat.

\section{PEMBAHASAN}

Seperti dipaparkan di bagian Pendahuluan, permasalahan yang dihadapi Paulus di Jemaat Korintus serupa dengan permasalahan yang dihadapi dalam penjangkauan anak muda di GBI Pasko Bandung. Oleh sebab itu strategi penggembalaan Paulus dalam menghadapi masalah di Jemaat Korintus cukup 
BONAFIDE: Jurnal Teologi dan Pendidikan Kristen

www.jurnal.sttissiau.ac.id/Volume 1/Nomor 2/Desember 2020/hal.279-292

relevan diterapkan dalam menghadapi menurunnya partisipasi anak muda dalam kegiatan ibadah di gereja ini.

\section{Menggembalakan Anak Muda dengan Komunikasi Positif}

Dalam menggembalakan Paulus menciptakan iklim postif melalui komunikasi yang baik. Komunikasi memegang peranan yang penting dalam kaitannya dengan pembentukan masyarakat karena melalui komunikasi manusia dapat saling berdekatan dalam suatu komunitas. Willbur Schrarmm menyatakan komunikasi sebagai suatu proses berbagi. Apabila berkomunikasi, sebenarnya sedang menumbuhkan suatu kebersamaan dengan seseorang, yaitu berusaha berbagi informasi, ide atau sikap.(dalam Hasmawati, 2018)

Dapat disimpulkan bahwa sebuah komunikasi berhasil melahirkan kebersamaan dan menghindari pengelompokan. Melalui komunikasi akan terciptanya hubungan yang baik. Dalam 2 Korintus 13:11 merupakan dasar komunikasi. Rasul Paulus memberikan nasehat untuk "Sehati sepikirlah kamu, dan hiduplah dalam damai sejahtera" yang menekankan orang percaya harus memiliki karakteristik ini dalam hubungan mereka dengan satu sama lain dalam membangun komunikasi yang harmonis dengan perkataan yang penuh kasih melalui sehati sepikir dan damai sejahtera sehingga perbedaan pendapat jangan sampai mengakibatkan hubungan kasih merenggang.

Hal ini penting di tengah-tengah jemaat dalam hal kurangnya komunikasi yang menyebabkan pengelompokkan. Namun, jika komunikasi yang baik ada di tengah-tengah jemaat akan mampu menciptakan suasana yang nyaman di tengahtengah jemaat, contohnya setiap jemaat yang membentuk kelompok-kelompok 
BONAFIDE: Jurnal Teologi dan Pendidikan Kristen

www.jurnal.sttissiau.ac.id/Volume 1/Nomor 2/Desember 2020/hal.279-292

harus berinteraksi dengan kelompok-kelompok yang ada di tengah-tengah jemaat sehingga terciptanya komunikasi. Komunikasi yang baik akan menciptakan kedekatan antar pribadi di tengah-tengah jemaat. Dengan terciptanya komunikasi di dalam jemaat maka jemaat menjadi produktif karena semua jemaat fokus pada tujuan mereka sebagai murid Kristus.

Kepada anak-anak muda yang menjauh dari persekutuan perlu didekati dengan pola komunikasi yang baik agar mereka bisa memahami situasi yang terjadi secara dewasa. Begitu juga, untuk mempertahankan mereka dalam persekutuan perlu komunikasi yang intens dengan mereka.

\section{Mengajak Anak Muda Menghadapi Perbedaan Secara Dewasa}

Konflik yang terjadi di berbagai komunitas selalu berpotensi mengakibatkan perpecahan bila tidak dihadapi dengan sikap dewasa. Paulus menilai bahwa konflik di jemaat Korintus diakibatkan oleh ketidakdewasaan jemaat. Jadi untuk bisa hidup berdamai dengan orang lain, seseorang harus bersikap dewasa. Dewasa dalam hal ini adalah dewasa secara rohani.

Kaum muda adalah orang yang sudah dewasa. Hurlock menempatkan mereka pada kategori dewasa awal, yaitu usia 18 - 40 tahun. Pada usia ini, pemuda telah mengalami perkembangan kognitif, emosi, dan sosial yang lebih matang. (dalam Sukaesih, 2017) Menurut Surachmad (1997:51-52) mereka telah memiliki dasar-dasar yang kuat untuk mendapatkan pengalaman dan pengetahuan dalam banyak lapangan, yang menjadi daya kritis dengan semakin banyak minat 
BONAFIDE: Jurnal Teologi dan Pendidikan Kristen

www.jurnal.sttissiau.ac.id/Volume 1/Nomor 2/Desember 2020/hal.279-292

kepada soal-soal teoritis. (dalam Putri, 2019). Dengan kondisi, kaum muda mestinya sudah bisa diajak untuk memahami situasi pelayanan dengan baik.

Sutanto mengatakan bahwa kedewasaan rohani seseorang bukan ditentukan dari berapa lama ia sudah menjadi Kristen. Bukan ditentukan dari berapa tinggi jabatannya di gereja. Bukan pula ditentukan dari kesibukannya dalam pelayanan. Dalam tulisan Paulus ini, indikator kedewasaan itu adalah hidup tanpa iri hati dan perselisihan.(Sutanto, 2016)

Apa yang menjadi perselisihan di jemaat Korintus, bagi Paulus sebenarnya adalah hal yang "remeh". Paulus terkejut bahwa hal tersebut menjadi sumber konflik di jemaat. (Third Millenium Ministries, 2012) Namun begitulah, meskipun remeh namun karena tidak dihadapi dengan sikap dewasa akhirnya menjadi sumber konflik. Menurut Gulo, Paulus memahami bahwa setiap jemaat memiliki potensi konflik. Namun persolan di Korintus mereka tidak dapat menyelesaikan konflik tersebut secara kristiani dan kemudian hidup dalam kesehatian dan satu pikir. (1Kor. 1:10). (Gulo, 2013)

Kepada anak muda perlu ditekankan bahwa dalam pelayanan tidak ada seorang yang lebih utama dari yang lain. Siapapun yang terlibat dalam pelayanan, semuanya adalah hamba Tuhan, mereka bekerja hanya untuk Tuhan. Konflik di Korintus juga disebabkan karena adanya pemujaan terhadap tokoh tertentu. Fanatisme berlebih terhadap satu atau lebih orang seperti ini disebut Paulus sebagai ciri dari manusia duniawi. "Aku dari golongan Paulus," dan yang lain berkata: "Aku dari golongan Apolos, " bukankah hal itu menunjukkan, bahwa kamu manusia duniawi yang bukan rohani?(3:4).(Slawi, 2016) Pada ayat 6-7 
BONAFIDE: Jurnal Teologi dan Pendidikan Kristen

www.jurnal.sttissiau.ac.id/Volume 1/Nomor 2/Desember 2020/hal.279-292

Paulus mengatakan "Aku menanam, Apolos menyiram, tetapi Allah yang memberi pertumbuhan. Karena itu yang penting bukanlah yang menanam atau yang menyiram, melainkan Allah yang memberi pertumbuhan.

\section{Menguatkan Iman Anak Muda dengan Pengajaran}

Meskipun terdapat perbedaan dalam pelayanan, bahkan tidak jarang termasuk perbedaan dalam ajaran, namun anak muda perlu terus diajak untuk menggali dan memahami Firman Tuhan. Melalui persekutuan dan komunikasikomunikasi yang dibangun dengan mereka pengajaran mengenai Firman Tuhan tetap penting untuk dilakukan. Dengan usia yang sudah memasuki tahap dewasa mestinya mereka bisa menemukan jawaban atas pertanyaan-pertanyaan mereka yang selama ini membuat mereka tawar hati dan menjauh dari persekutuan.

\section{KESIMPULAN}

Strategi penggembalaan Paulus memiliki relevansi bagi penjangkauan anak muda di GBI Pasko Bandung. Tiga poin yang relevan adalah komunikasi yang baik, menghadapi perbedaan secara dewasa, dan menguatkan iman anak muda dengan pengajaran Firman Tuhan.

Dalam konteks zaman modern dapat memanfaatkan teknologi yang canggih dalam berkomunikasi menyampaikan pengajaran, seperti mengirimkan video khotbah-khotbah atau kata-kata yang menguatkan lewat whats app, Instagram, Facebook dan lain sebagainya untuk memberikan pengajaran pokok iman dalam mendewasakan iman anak muda. Strategi penggembalaan Rasul Paulus dapat 
BONAFIDE: Jurnal Teologi dan Pendidikan Kristen

www.jurnal.sttissiau.ac.id/Volume 1/Nomor 2/Desember 2020/hal.279-292

diringkaskan oleh kata-kata seperti memberi dorongan, memberi kemampuan, uraian, teladan, dan nasihat.

\section{DAFTAR PUSTAKA}

Bons-Storm, M. (1967). Apakah Penggembalaan Itu? BPK Gunung Mulia.

Filadelfia. (2015). Perpecahan Gereja Di Korintus Dan Solusi Paulus Sebagai Prinsip Bagi Gereja Masa Kini. Filadelfia. http://filadelfiadumai. blogspot.com/2015/05/perpecahan-gereja-di-korintus-dan.html

Gereja Yesus Kristus. (n.d.). Surat-Surat Paulus. churchofjesuschrist.org. Diambil 22 Desember 2020, dari https://www.churchofjesuschrist.org/study/ scriptures/gs/pauline-epistles?lang=ind

Gulo, M. R. (2013). KONFLIK MENURUT PAULUS DALAM 1 KORINTUS $3: 1$ 9. mustikarantogulo.wordpress.com. https://mustikarantogulo.wordpress. com/2013/06/19/712/

Hasmawati, F. (2018). MANAJEMEN DALAM KOMUNIKASI. Al-Idarah: Jurnal Pengkajian Dakwah dan Manajemen, 5(6), 76-86. https://doi.org/10.37064/AI.V5I6.4830

Hura, F. (2020). Pengaruh Komunikasi Gembala Sidang Terhadap Keaktifan Pengerja Gereja. Antusias: Jurnal Teologi dan Pelayanan, 6(1), 32-45.

Putri, A. F. (2019). Pentingnya Orang Dewasa Awal Menyelesaikan Tugas Perkembangannya. SCHOULID: Indonesian Journal of School Counseling, 3(2), 35-40. https://doi.org/10.23916/08430011

Rupa, C. S. (2016). CIRI KHAS SEORANG GEMBALA BERDASARKAN PERSPEKTIF 1 PETRUS 5:1-4 . JURNAL JAFFRAY, 14(2), 165-188.

Slawi. (2016). Fokus Terhadap Berita, Bukan Pewarta (1 Korintus 3:1-9). BS Ministry. https://bsministry.id/news/view/11/fokus-terhadap-berita-bukanpewarta-1korintus-31-9

Sudjarwo, M. (2019). Mengaplikasikan Integritas Gembala Jemaat Menurut Surat-surat Penggembalaan. EPIGRAPHE: Jurnal Teologi dan Pelayanan Kristiani, 3(2), 173-189. https://doi.org/10.33991/epigraphe.v3i2.47

Sukaesih, T. (2017). Pendidikan Keimanan Bagi Usia Dewasa Awal Menurut Perspektif Islam. UIN Raden Intan Lampung.

Sutanto, O. (2016). DEWASA DALAM KRISTUS. Renungan Harian. http://www.renunganharian.net/2016/75-maret/1721-dewasa-dalamkristus.html

Telaumbanua, A. (2019). Peran Gembala Sidang Sebagai Pendidik Dalam 
BONAFIDE: Jurnal Teologi dan Pendidikan Kristen

www.jurnal.sttissiau.ac.id/Volume 1/Nomor 2/Desember 2020/hal.279-292

Pertumbuhan Rohani Jemaat. FIDEI: Jurnal Teologi Sistematika dan Praktika, 2(2), 362-387. https://doi.org/10.34081/fidei.v2i2.45

Third Millenium Ministries. (2012). Intisari Teologi Paulus: Pelajaran Empat, Paulus dan Jemaat Korintus. Third Millenium Ministries. http://thirdmill.org.

Wijaya, H. (2012). Komunikasi dalam Pelayanan Masa Kini. In Sekolah Tinggi Theologia Jaffray. https://www.researchgate.net/publication/282854615_ Komunikasi_dalam_Pelayanan_Masa_Kini

Yusmasari, C. P. (2018). Menggali Inspirasi dari Pertobatan Rasul Paulus Demi Pengembangan Spiritualitas Katekis Zaman Sekarang. Fakultas Ilmu Keguruan dan Ilmu Pendidikan Universitas Sanata Dharma. 